\title{
Understanding the Use of Phosphine-(EWO) Ligands in Negishi Cross-Coupling: Experimental and Density Functional Theory Mechanistic Study
}

\author{
Estefanía Gioria, Juan del Pozo, Agustí Lledós, and Pablo Espinet* \\ Cite This: Organometallics 2021, 40, 2272-2282 \\ Read Online
}

ACCESS | Lill Metrics \& More | 国 Article Recommendations | (1) Supporting Information

ABSTRACT: The easily prepared hemilabile ligand 1- $\left(\mathrm{PPh}_{2}\right), 2-($ trans$\mathrm{CH}=\mathrm{CHCOPh})-\mathrm{C}_{6} \mathrm{~F}_{4}$ (PhPEWO-F) and other PEWO ligands are well-known promoters of $\mathrm{C}-\mathrm{C}$ reductive eliminations and very effective in Negishi couplings. As an example, the efficient Negishi coupling of $\left(\mathrm{C}_{6} \mathrm{~F}_{5}\right)-\mathrm{I}$ and $\mathrm{Zn}\left(\mathrm{C}_{6} \mathrm{~F}_{5}\right)_{2}$ is reported. The thorough experimental study of the steps involved in the catalytic cycle uncovers the potential weakness of this ligand that could frustrate at some points the desired cycle and provide some simple precautions to keep the catalytic cycle working efficiently. Density functional theory (DFT) calculations complete the experimental study and provide insight into nonobservable transition states and intermediates, comparing the potential conflict between reductive elimination and olefin insertion. Our results showcase the importance the transmetalation step, facilitated by the strong trans effect of the electron-withdrawing ligand, and the choice of organozinc nucleophiles, critical to ensure fast group exchange and a positive outcome of the catalytic reactions.

\section{INTRODUCTION}

Reductive elimination is the irreversible step that pulls forward the whole catalytic cycle in all $\mathrm{C}-\mathrm{C}$ cross-coupling reactions. Reported computed $\mathrm{C}-\mathrm{C}$ coupling activation energies in the gas phase are, for conventional ligands such as phosphines, in the broad range of $0.6-28.6 \mathrm{kcal} / \mathrm{mol}$, the coupling barrier increasing in the order vinyl-vinyl $<\mathrm{Ph}-\mathrm{Ph}<\mathrm{Me}-\mathrm{Me}{ }^{1}$ Experimental observations additionally support the order $\mathrm{Me}-$ $\mathrm{Me}<\mathrm{C}_{6} \mathrm{~F}_{5}-\mathrm{Me}<\mathrm{C}_{6} \mathrm{~F}_{5}-\mathrm{C}_{6} \mathrm{~F}_{5}{ }^{2}$ Extremely difficult are $\mathrm{Ar}-\mathrm{CF}_{3}$ couplings (also $\mathrm{Ar}-\mathrm{F}$ ), for which only few successful reports are found in the literature. ${ }^{3,4}$ For this reason, lowering the reductive elimination barrier can be critical for the efficiency and selectivity of any coupling process facing other potentially competitive courses.

Electron-withdrawing olefins (EWO) are powerful coupling inducers in Pd chemistry that can lower the coupling barriers by $10-12 \mathrm{kcal} \mathrm{mol}^{-1}$ relative to conventional ligands, as shown in the case of $\mathrm{Me}-\mathrm{Me}$ coupling. ${ }^{5}$ The reason is that, when coordinated to $\mathrm{Pd}$, they behave as electron-withdrawing groups, stabilizing the transition state for reductive elimination where evolution from $\mathrm{Pd}^{\mathrm{II}}$ to $\mathrm{Pd}^{0}$ increases the electron density of the Pd center. This explains why the presence of EWO groups in the reagents can facilitate coupling processes that do not occur in stoichiometric conditions. ${ }^{6}$ Since back-donation from $\mathrm{Pd}^{\mathrm{II}}$ is only moderate, EWO groups are not good ligands for $\mathrm{Pd}^{\mathrm{II}}$, and their use as coupling additive might require large $\mathrm{EWO} / \mathrm{Pd}$ ratios to achieve coordination. This inconvenience

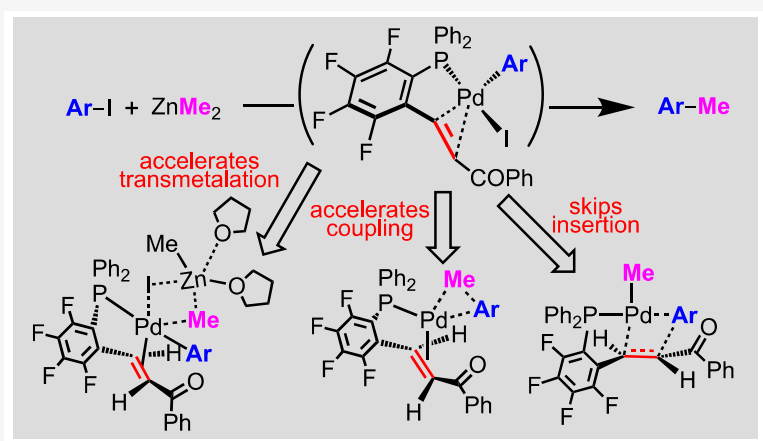

can be overcome by integrating the EWO group into a chelating ligand with a strong coordinating donor atom. This is the case of the PEWO ligands considered here (Figure 1),<smiles>O=C(/C=C/c1ccccc1/N=C/O)c1ccccc1</smiles><smiles>O=C(/C=C/c1c(F)c(F)c(F)c(F)c1P(=O)(O)O)c1ccccc1</smiles>

Figure 1. Classic and fluorinated PEWO ligands.

displaying a phosphine $(\mathrm{P})$ and an electron-withdrawing olefin (EWO) as coordinating functions. Ligands of the kind RPEWO-H were soon used in Suzuki and, more often, in Negishi catalysis ${ }^{7}$ and afforded noticeably better results than common monodentate phosphines such as $\mathrm{PPh}_{3}$. As expected, a $\mathrm{PEWO} / \mathrm{Pd}=1: 1$ ratio was more efficient than a $2: 1$ ratio, since the EWO effect should require chelating coordination. ${ }^{7 c}$ These ligands turned out to be very efficient to minimize the

Special Issue: Organometallic Solutions to Challenges in Cross-Coupling

Received: January 1, 2021

Published: March 26, 2021

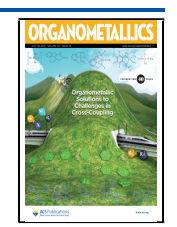


formation of the so-called "reduction product" $\mathrm{Ar}-\mathrm{H}$ during aryl-alkyl coupling. $\mathrm{Ar}-\mathrm{H}$ was assumed to arise from $\beta$-H elimination of $[\mathrm{PdAr}($ alkyl $)]$ intermediates followed by $\mathrm{Ar}-\mathrm{H}$ coupling, and faster aryl-alkyl coupling would prevent slower formation of the hydride.

Several years later, we reported similar fluorinated ligands RPEWO-F. Fluorination makes them stronger electron acceptors, not only at the EWO but also at the $\mathrm{P}$ atom, and more resistant to $\mathrm{P}$ oxidation. Important structural information on the catalysts can be obtained by ${ }^{19} \mathrm{~F}$ NMR, and they are easier to crystallize, providing some additional information on the reactions. ${ }^{8}$ We could, for instance, demonstrate that the "reduction" product $\mathrm{Ar}-\mathrm{H}$ came from hydrolysis of $\mathrm{ZnArMe}$ byproducts formed in undesired $\mathrm{Pd} / \mathrm{Zn}$ transmetalations and not significantly from $\beta$-H elimination. Remarkably, the fluorinated RPEWO-F were found to be noticeably more effective than their hydrogen homologues in lowering the activation energy of the reductive elimination step.

In this respect, the experimental coupling activation barriers for Pf-Pf coupling ( $\mathrm{Pf}=\mathrm{C}_{6} \mathrm{~F}_{5}$ ) can be determined from preformed cis- $\left[\mathrm{M}\left(\mathrm{C}_{6} \mathrm{~F}_{5}\right)_{2}(\mathrm{THF})_{2}\right]$ upon addition of PEWO $\left(\mathrm{M}=\mathrm{Pd},{ }^{9} \mathrm{Ni}{ }^{10}{ }^{1} \mathrm{THF}=\right.$ tetrahydrofuran $)$. The experimental energy barriers at $25{ }^{\circ} \mathrm{C}$ for $\mathrm{Pd}$ complexes, $\left(\Delta G_{\mathrm{Pf}-\mathrm{Pf}}^{\neq}\right)_{\mathrm{Pd}}$, were determined to be $24.6 \mathrm{kcal} \mathrm{mol}^{-1}$ PhPEWO-H and $22.3 \mathrm{kcal}$ $\mathrm{mol}^{-1}$ for PhPEWO-F. ${ }^{9}$ Both PEWO ligands behave even better on Ni: $\left(\Delta G_{\mathrm{Pf}-\mathrm{Pf}}^{\ddagger}\right)_{\mathrm{Ni}}=19.9 \mathrm{kcal} \mathrm{mol}^{-1}$ for PhPEWO-H vs $17.7 \mathrm{kcal} \mathrm{mol}^{-1}$ for PhPEWO-F at $0{ }^{\circ} \mathrm{C} .{ }^{10}$ For both metals, the coupling barriers are much lower for the fluorinated PEWO. Remarkably, both Ni-PEWO complexes undergo quantitative coupling in $8 \mathrm{~h}$ at $-50{ }^{\circ} \mathrm{C}$ ! It looks that PEWO ligands can be particularly efficient with challenging groups such as fluorinated aryls, and no other ligand gets close to this in $\mathrm{Ni}$ catalysis. The difference in activation energy between PhPEWO-H and PhPEWO-F, whether in Pd or Ni complexes, translates into effective rates that are tens of times faster for the later. This can result in significantly lower reaction temperatures or outcompeting undesired side reactions.

The Negishi process is often the methodology of choice for cross-couplings involving alkyl groups. ${ }^{11}$ The synthetic scope of this reaction is broad, as organozinc compounds are easy to make, stable, and compatible with most functional groups. ${ }^{12-14}$ The most frequent couplings, even those involving difficult $\mathrm{sp}^{3}$ groups, can be achieved very efficiently using bulky biarylphosphine or NHC ligands. Mechanistic investigations on the individual steps of these catalytic cycles are available: the reversibility of the transmetalation, a step that we have studied for $\mathrm{ZnMe}_{2}, \mathrm{ZnEt}_{2}$, and $\mathrm{ZnMeCl}$ reagents, ${ }^{15}$ which can give rise to homocoupling in detriment of cross-coupling products; $^{15 \mathrm{~d}, 16}$ the usually positive effect of zincates, true nucleophiles passing unnoticed to exist in solution in early catalytic reports but well recognized today; ${ }^{13,14 \mathrm{c}}$ the role of additives such as inorganic salts; ${ }^{14}$ or the influence of the solvents. $^{13,14,17}$

Clearly, without neglecting the importance of the reductive elimination, catalytic Negishi processes are more complicated than just this single irreversible step. Although there is reasonable evidence that a $1: 1 \mathrm{PEWO} / \mathrm{Pd}$ ratio, favoring chelation, is needed for their optimal activity, there is uncertainty about the fate of a multifaceted hemilabile PEWO ligand throughout the catalytic cycle, the effect, at each step, of having excess ligand present (which is a frequent routine procedure to better protect $\mathrm{Pd}$ catalysts from formation of $\mathrm{Pd}$ black), the possible weaknesses associated with the potential reactivity of the EWO group, or the consequences of using higher temperatures. Herein, we have conducted a detailed experimental and mechanistic study on the model coupling aryl-Me, using Negishi catalysis at room temperature, and $\mathrm{ZnMeCl}$ as the nucleophile. Since the role of $\beta$ - $\mathrm{H}$ elimination with PEWO was investigated in a previous study using $\mathrm{Et}^{8 \mathrm{~b}}$ we decided to study other aspects of the C$\mathrm{C}$ coupling with this ligand using a simpler system with $\mathrm{Me}$ as the nucleophile. The first section is dedicated to the experimental examination of each step in the cycle, and the second focuses on DFT calculations of the whole catalytic process and the possible competition of undesired olefin insertion, observed occasionally under some circumstances.

\section{RESULTS AND DISCUSSION}

Preliminary Test. Only very recently has catalytic $\mathrm{C}_{6} \mathrm{~F}_{5}-$ $\mathrm{C}_{6} \mathrm{~F}_{5}$ coupling been reported, by $\mathrm{Pd}$-catalyzed homocoupling of highly fluorinated arylboronates, using stoichiometric $\mathrm{Ag}_{2} \mathrm{O}$ as the oxidant. ${ }^{18}$ Our plan is to develop a Negishi catalysis that can afford not only homocoupling but also cross-coupling of fluorinated aryls, using the appropriate combination of fluoroaryl electrophile and fluoroaryl zincate. We have tested the viability of the process in the reaction in eq 1 , monitored in

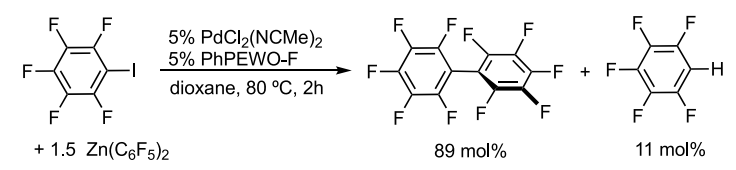

an NMR tube using $\mathrm{C}_{6} \mathrm{~F}_{6}$ as the internal standard.This very positive result is now being developed in our group into a full scope of fluorinated motifs. As far as the present study is concerned, since it takes place at $80{ }^{\circ} \mathrm{C}$, it invites one to examine the effect of temperatures higher than ambient on the activity and stability of Ph-PEWO-F in catalysis.

Part 1: Experimental Study of the Catalytic Steps. The studies in this section provide experimental information about each step of the catalytic cycle, analyzing potential complications of the PEWO behavior when used in PEWO/ $\mathrm{Pd}=1: 1$ or $2: 1$ ratios. The proposed Scheme 1 is shown in advance in order to facilitate the discussion that follows. The desired cycle is shown in black; in blue, we highlight the effect of a second PEWO molecule when in a 2:1 ratio. We have considered the sequence of reactions starting from two more convenient precatalysts $\mathbf{2}$ and $\mathbf{5}$.

1. Synthesis, In Situ Formation, and Structural Characterization of $\left[\mathrm{PdCl}_{2}(\mathrm{PhPEWO}-\mathrm{F})_{n}\right](n=1,2)$ Complexes. The in situ formation of the catalyst from an appropriate precursors is a frequent methodology in homogeneous catalysis. In our initial studies on the Negishi coupling of $2-\mathrm{I}-\mathrm{C}_{6} \mathrm{H}_{4}\left(\mathrm{CO}_{2} \mathrm{Et}\right)$ with $\mathrm{ZnEt}_{2}$, we reported in situ formation of the precatalyst $\left[\mathrm{PdCl}_{2}(\mathrm{PhPEWO}-\mathrm{F})\right]$ (2) from trans- $\left[\mathrm{PdCl}_{2}(\mathrm{NCMe})_{2}\right]$ and PhPEWO-F (1:1.05 ratio) in the presence of the electrophile, allowing $15 \mathrm{~min}$ before the nucleophile was added. ${ }^{8 \mathrm{a}}$ Precatalyst generation required this waiting period, which can be understood after monitoring by NMR at room temperature. We found that a two-step reaction takes place (Scheme 2 and NMR monitoring in Figure S1): Initially, trans$\left[\mathrm{PdCl}_{2}(\mathrm{PhPEWO}-\mathrm{F}-\mathrm{P})_{2}\right]$ (1), with two P-monodentate PhPEWO-F ligands, is instantaneously formed from half of the available trans- $\left[\mathrm{PdCl}_{2}(\mathrm{NCMe})_{2}\right]$ precursor. Then, $\mathbf{1}$ rearranges slowly to the desired precatalyst $\left[\mathrm{PdCl}_{2}(\mathrm{PhPEWO}-\mathrm{F}-\mathrm{chel})\right](2)$, containing a chelating PhPE- 
Scheme 1. Catalytic Cycle for the Pd-Catalyzed Coupling of $\mathrm{Ar}-\mathrm{I}$ with $\mathrm{ZnRCl}$, Including Possible Complications ${ }^{a}$

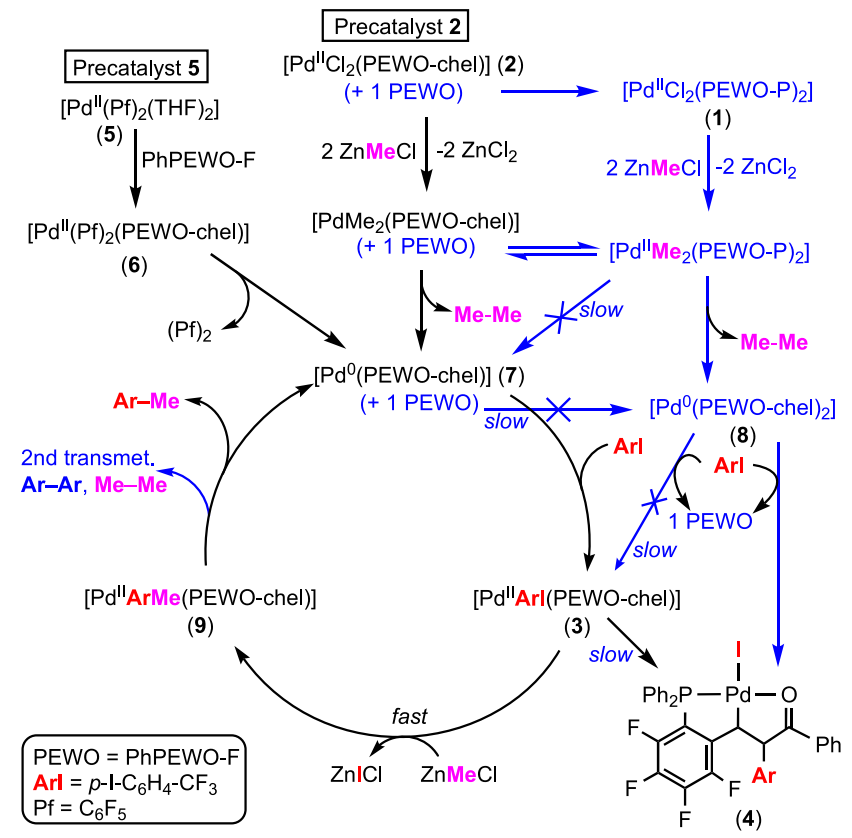

${ }^{a}$ PEWO stands for free PhPEWO-F; PEWO-P stands for monodentate P-coordinated; and PEWO-chel for chelating coordination.

Scheme 2. Pathway Observed in Formation of Precatalyst 2

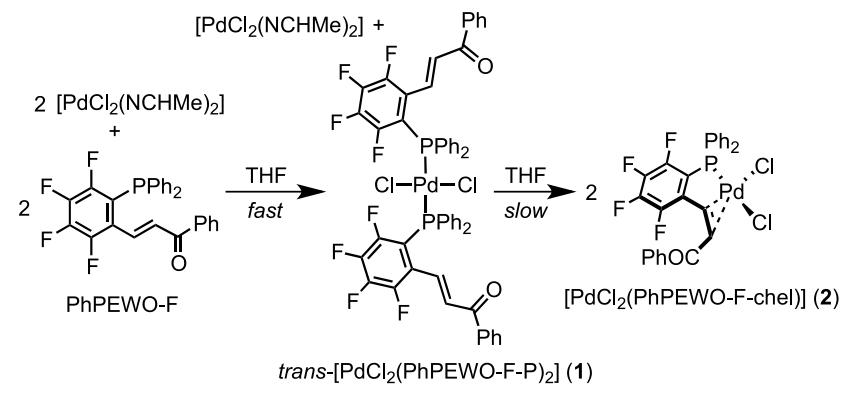

WO-F ligand. ${ }^{19}$ This suggests that the second $\mathrm{MeCN}$ substitution on a putative trans- $\left[\mathrm{PdCl}_{2}(\mathrm{PhPEWO}-\mathrm{F}-\mathrm{P})\right.$ $(\mathrm{NCMe})]$ intermediate is faster than the first substitution on trans- $\left[\mathrm{PdCl}_{2}(\mathrm{NCMe})_{2}\right]$. This kinetic behavior is to be expected from the trans-effect of the two ligands involved (phosphine > $\mathrm{NCMe}$ ) and also from their trans-influence (phosphine > $\mathrm{NCMe}$ in both cases). Hence, it is the expected result regardless of the ligand substitution mechanism (associative or dissociative). It takes $15 \mathrm{~min}$ at room temperature to reach $85 \%$ conversion to complex 2 (Figure S1). At lower temperatures $\left(20^{\circ} \mathrm{C}\right)$, a $\left[\mathrm{PdCl}_{2}\{E-(\mathrm{Ph}-\mathrm{PEWO}-\mathrm{F})\}\right]$ complex is observed in the ${ }^{1} \mathrm{H}$ NMR spectra, whereas the X-ray structure of the final product 2 shows a $Z$ configuration for the coordinated EWO group. ${ }^{20}$

Complex trans- $\left[\mathrm{PdCl}_{2}(\mathrm{PhPEWO}-\mathrm{F}-\mathrm{P})_{2}\right]$ (1) is the final product for $\mathrm{PEWO} / \mathrm{Pd}=2: 1$ ratio. Since the EWO group is not coordinated, complex 1 behaves quite similar to trans$\left[\mathrm{PdCl}_{2}\left(\mathrm{PPh}_{3}\right)_{2}\right]$, at least at room temperature. This makes it less efficient at the reductive elimination step. ${ }^{8 a}$ Moreover, reductive elimination via double methylation (right side of Scheme 1) will form the fairly unreactive $\mathrm{Pd}^{0}$ complex $\left[\mathrm{Pd}(\mathrm{PhPEWO}-\mathrm{F}-\mathrm{chel})_{2}\right](\mathbf{8})$, which cannot be easily reinjected into the catalytic cycle by oxidative addition (see step 3 ). It has a considerable oxidation barrier compared to the reactive $\mathrm{Pd}^{0}$ complex $[\mathrm{Pd}(\mathrm{PhPEWO}-\mathrm{F}-\mathrm{chel})]$ (7). For this reason, the waiting time of at least $15 \mathrm{~min}$ is necessary in order to ensure that the catalysis starts with most of the $\mathrm{Pd}$ in the form of precatalyst 2 .

2. Entering the Cycle via $\left[\mathrm{Pd}^{0}(P h P E W O-F-c h e l)\right]$. Two precatalysts are most efficient to enter the catalytic cycle via [Pd(PhPEWO-F-chel)] (7), keeping a Pd/PEWO-F = 1:1 ratio:

(i) Precatalyst 2: $\left[\mathrm{PdCl}_{2}(\mathrm{PhPEWO}-\mathrm{F}-\mathrm{chel})\right]$ (2) eventually provides the $\mathrm{Pd}^{0}$ catalyst $[\mathrm{Pd}(\mathrm{PhPEWO}-\mathrm{F}-$ chel $)]$ (7) after double transmetalation with 2 equiv of the organometallic nucleophile (e.g., $\mathrm{ZnMeCl}$ ), followed by efficient reductive elimination of $\mathrm{R}-\mathrm{R}$. This is a convenient mode of operation.

(ii) Precatalyst 5: Alternatively, the storable complex cis$\left[\mathrm{Pd}\left(\mathrm{C}_{6} \mathrm{~F}_{5}\right)_{2}(\mathrm{THF})_{2}\right](5)$ is a more general precatalyst that can be precursor to many $\mathrm{Pd}^{\mathrm{II}}$ complexes, including 6 and therefrom producing [Pd(PhPEWO-F-chel)] (7) (left side of Scheme 1). $\mathrm{Pd}^{0}$ complexes with other chelating PEWO species or with many other ligands are accessible upon ligand substitution of $5,{ }^{9}$ which only leaves the quite inert decafluoribiphenyl as a residue.

Although precatalyst $\mathbf{2}$ may look more convenient, it will fail if the pathway to 7 is not efficient because $\left[\mathrm{PdR}_{2}\right.$ ( $\mathrm{PhPEWO}-\mathrm{F}-$ chel)] is inaccessible. This is observed in the results of the reaction in eq 2 , summarized in Table 1 . Catalyst $\mathbf{2}$ is very

$$
\text { (2.5) } \mathrm{ZnRCl} \underset{25^{\circ} \mathrm{C}, 2 \mathrm{~h}}{5 \% \text { or } 6, \mathrm{THF}} \stackrel{\mathrm{CO}_{2} \mathrm{Et}}{\mathrm{CO}_{2} \mathrm{Et}}+\mathrm{ZnICl}
$$

Table 1. Catalytic Results for Equation $2^{a}$

\begin{tabular}{clccc} 
entry & \multicolumn{1}{c}{$\mathrm{R}$} & {$[\mathrm{Pd}]$} & $t(\mathrm{~h}) / \mathrm{T}\left({ }^{\circ} \mathrm{C}\right)$ & $\mathrm{Ar}-\mathrm{R} \%$ \\
\hline 1 & $\mathrm{Et}^{b}$ & $\mathbf{2}$ & $2 / 25$ & 94 \\
2 & $i-\mathrm{Pr}^{c}$ & $\mathbf{2}$ & $2 / 25$ & $94^{e}$ \\
3 & $\mathrm{Cy}^{c}$ & $\mathbf{2}$ & $2 / 25$ & 91 \\
4 & $n-\mathrm{Bu}^{d}$ & $\mathbf{2}$ & $2 / 25$ & 91 \\
5 & $t-\mathrm{Bu}^{c}$ & $\mathbf{2}$ & $2 / 25$ & $14^{f}$ \\
6 & ${ }^{t} \mathrm{Bu}^{c}$ & $\mathbf{6}$ & $2 / 25$ & $57^{f}$
\end{tabular}

${ }^{a}$ Experimental conditions: $\mathrm{Ar}-\mathrm{I} 1(0.1 \mathrm{mmol}), \mathrm{ZnRCl}(0.25 \mathrm{mmol})$, [Pd] $(0.005 \mathrm{mmol})$, in THF (total volume $=1.5 \mathrm{~mL}$ ). Yield was determined by GC-MS. ${ }^{b} \mathrm{ZnRCl}$ was prepared in situ by reacting $\mathrm{R}_{2} \mathrm{Zn}$ $+\mathrm{ZnCl}_{2} \cdot{ }^{c} \mathrm{RZnCl}$ was prepared by reacting $\mathrm{RMgX}+\mathrm{ZnCl}_{2} \cdot{ }^{a} \mathrm{RZnX}$ was prepared by reacting $\mathrm{RLi}+\mathrm{ZnCl}_{2}$. ${ }^{e}$ Linear/branched $=40: 60$. $f_{\text {Final } \mathrm{R}}=\mathrm{CH}_{2} \mathrm{CHMe}_{2}$.

efficient for many nucleophiles susceptible to "reduction", including $n$ - $\mathrm{Bu}$ (entry 4) but fails in the case of using ${ }^{t} \mathrm{BuZnCl}$ (entry 5), where two ${ }^{t} \mathrm{Bu}$ groups would need to overcome serious steric repulsion to form $\left[\mathrm{Pd}\left({ }^{t} \mathrm{Bu}\right)_{2}(\mathrm{PhPEWO}-\mathrm{F}-\mathrm{chel})\right]$. The reaction works much better if $[\mathrm{Pd}(\mathrm{PhPEWO}-\mathrm{F}-\mathrm{chel})]$ is generated directly from 5 (entry 6). The reaction is anyhow reluctant to produce the quaternary product, and the product of H-migration is obtained.

3. Potential Complexity at the Oxidative Addition Step: $\left[\mathrm{Pd}^{0}\left(\mathrm{PhPEWO}-\mathrm{F}\right.\right.$-Chel)] (7) vs $\left[\mathrm{Pd}^{0}(\mathrm{PhPEWO}-\mathrm{F} \text {-chel })_{2}\right]$ (8) Reoxidation. The oxidative addition of $\mathrm{Ar}-\mathrm{I}$ on $\left[\mathrm{Pd}^{0}(\mathrm{PhPEWO}-\mathrm{F})\right](7)$ in solution is fast at $25^{\circ} \mathrm{C}$ and affords [PdArI(PhPEWO-F-(chel))] complexes 3, from which the cycle can continue. If free PEWO is present (blue pathways in 
Scheme 3. Proposed Evolution of the Reaction in Table 1, Entry 6

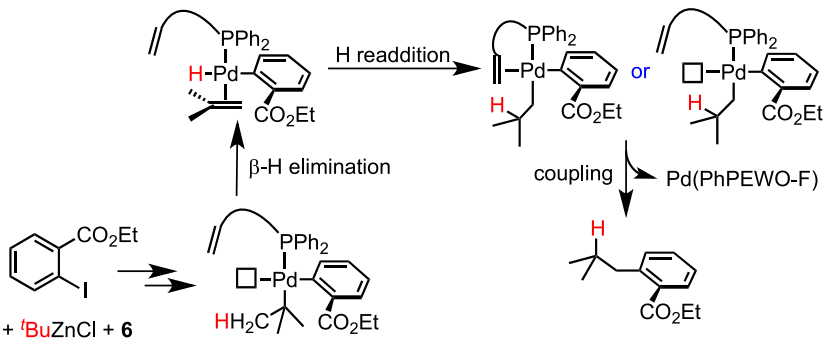

Scheme 1) it could displace the coordinated EWO group, giving rise to 8. Luckily, this problem does not occur if 7 has been correctly preformed, because the coordination of a second PEWO to 7 turns out to be slower than the oxidation of 7 by $\mathrm{Ar}-\mathrm{I}$, at least in the reactions studied here.

Complex $\left[\mathrm{Pd}^{0}(\mathrm{PhPEWO}-\mathrm{F}-\mathrm{chel})\right](7)$ is a nonisolable and highly reactive unsaturated species that in solution is probably somewhat stabilized by interactions with the solvent. In contrast, complex $\left[\mathrm{Pd}^{0}(\mathrm{PhPEWO}-\mathrm{F})_{2}\right]$ (8) can be formed from 2, 5, or 1 under noncatalytic conditions (absence of $\mathrm{Ar}-$ I), using $\mathrm{PEWO} / \mathrm{Pd}=2: 1$ ratio, or directly by ligand substitution on $\operatorname{Pd}_{2}(\mathrm{dba})_{3}$. It is very stable and can be isolated as a deep red solid. Its X-ray structure is shown in Figure 2.

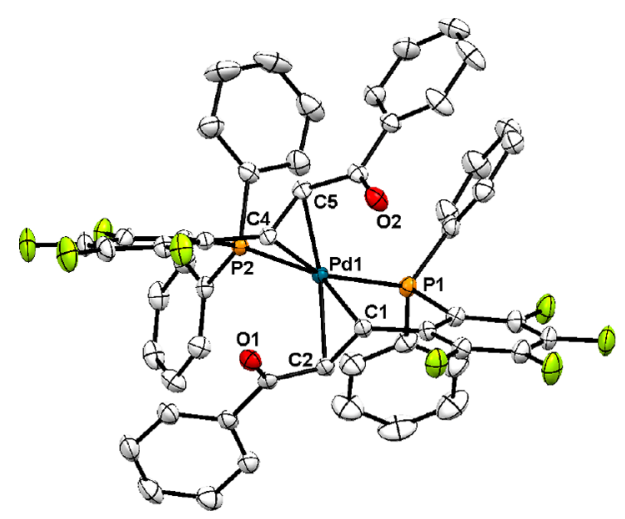

Figure 2. Structure of $\left[\mathrm{Pd}(\mathrm{PhPEWO}-\mathrm{F}-\mathrm{chel})_{2}\right](8)$, with thermal ellipsoids drawn at the $50 \%$ probability level. Co-crystallized hexanes as well as hydrogen atoms are omitted for clarity. The configuration of the double bonds is $E$.

Although produced as a racemic mixture, $\mathbf{8}$ displays a chiral distorted tetrahedral coordination around $\mathrm{Pd}^{0}$, defined by the two $\mathrm{P}$ atoms and the centers of the two $E$ double bonds. The plane formed by Pd and the midpoints of the double bonds makes a $52.9^{\circ}$ angle with the $\mathrm{PdP}_{2}$ plane (expected angle: $0^{\circ}$ for square-planar and $90^{\circ}$ for tetrahedral). The $\mathrm{P} 1-\mathrm{Pd}-\mathrm{P} 2$ angle is $111.91^{\circ}$, and the angle at $\mathrm{Pd}$ of the midpoints of the double bonds is $107.82^{\circ}$. The lengths of the double bonds are $(\mathrm{C} 1=\mathrm{C} 2)=1.442(4) \AA$ and $(\mathrm{C} 4=\mathrm{C} 5)=1.411(4) \AA$. This structure is very similar to the one reported for [ $\mathrm{Pd}(\mathrm{PhPEWO}-$ $\mathrm{H}$-chel $)_{2}$ ], slightly longer in 8 than in the reported [Pd$\left.(\mathrm{PhPEWO}-\mathrm{H}-\mathrm{chel})_{2}\right](\mathrm{C}=\mathrm{C}$ average $=1.406(4) \AA),{ }^{7 \mathrm{c}}$ which supports higher Pd-to-EWO back-donation in $\mathbf{8}$.

According to their very unlike nature, 7 and 8 behave very differently versus $\mathrm{Ar}-\mathrm{I}$ as oxidant, and different pathways are possible to continue the cycle, depending on the $\mathrm{Pd}^{0}$ complex formed. These are summarized in Scheme 4.
Scheme 4. Competitive Reactions at the Oxidative Addition Step

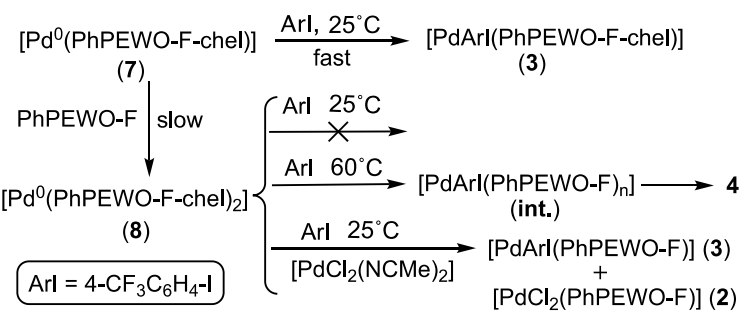

The oxidative addition of $\mathrm{Ar}-\mathrm{I}$ on $\left[\mathrm{Pd}^{0}(\mathrm{PhPEWO}-\mathrm{F})\right]$ (7) in solution is reasonably fast at $25{ }^{\circ} \mathrm{C}$, and it immediately affords [PdArI(PhPEWO-F-(chel)) $]$ (3), from which the cycle can continue. If free PEWO were present, it might displace the coordinated EWO group, giving rise to 8 (blue pathways in Scheme 1). Luckily, this problem does not occur in practice because the coordination of a second PEWO to 7 turns out to be slower than the oxidation of 7 by $\mathrm{Ar}-\mathrm{I}$, at least in the conditions studied here.

Complex $\mathbf{8}$ is remarkably air and moisture insensitive, highly stable in solution, and quite reluctant to oxidative addition by $\mathrm{Ar}-\mathrm{I}$ at room temperature. However, heating at $60{ }^{\circ} \mathrm{C}$ in $\mathrm{THF}$ $\left(\mathrm{Pd} / 4-\mathrm{CF}_{3} \mathrm{C}_{6} \mathrm{H}_{4}-\mathrm{I}=1: 3\right)$ produces oxidative addition (Scheme 3) followed by migratory insertion to complex 4 (see structure in Scheme 4), which suggests that this moderate temperature increase probably induces some entropically favored EWO decoordination from 8, favoring oxidative addition through a different intermediate (int.) than in the case of 7. Evolution of this intermediate in the reaction conditions leads to 4 instead of 3 . Interestingly, the oxidative addition of $\mathbf{8}$ at room temperature can be promoted by addition of $\left[\mathrm{PdCl}_{2}(\mathrm{NCMe})_{2}\right]$, which scavenges PhPEWO-F to give 7 (and therefrom 3 ) and 2 . This observation suggests possible rearrangements that might be operating to restore $\mathrm{PEWO} / \mathrm{Pd}=1: 1$ ratios under catalytic conditions.

We first observed the insertion product 4 in a reaction planned to obtain 3 according to Scheme $5 .^{21}$ This suggests that the nature of the intermediate labeled int. is probably trans- $\left[\mathrm{PdArI}(\mathrm{PhPEWO}-\mathrm{F})_{2}\right]$, which similarly undergoes fast migratory insertion at $60{ }^{\circ} \mathrm{C}$.

Scheme 5. Insertion Pathway Observed in the Reaction of PhPEWO-F with $\left[\mathrm{Pd}\left(4-\mathrm{CF}_{3} \mathrm{C}_{6} \mathrm{H}_{4}\right) \mathrm{I}\left(\mathrm{AsPh}_{3}\right)_{2}\right]$

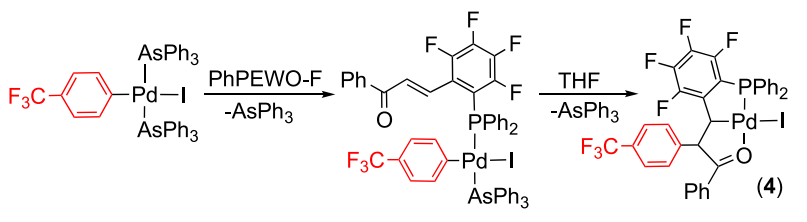

In order to evaluate the catalytic significance of the experiments in Schemes 3 and 4, we have to have to keep in mind that they are carried out in the absence of a nucleophile. This means that a subsequent transmetalation following the oxidative addition of $\mathrm{Ar}-\mathrm{I}$ is excluded. In the presence of $\mathrm{ZnMeCl}$ (Scheme 1), the catalysis works fine and $\mathbf{4}$ is not observed, suggesting that the sequence transmetalation followed by reductive elimination is faster than migratory insertion. These observations are supported by our computational studies in Part 2. In general, however, considering the reversibility of the transmetalation and instances where 
transmetalation is slow (depending on the nucleophile used), irreversible migratory insertion might be competitive.

4. Transmetalation Step vs Other Potentially Competing Processes. From all the previous comments, it is clear that a slow transmetalation can be the source of different problems as much as a slow reductive elimination. We have addressed these questions in the computational section in Part 2. Furthermore, since transmetalation is the most studied step of cross-coupling cycles, we refer the reader to the abundant literature available. $^{12-18}$

It is worth mentioning that our DFT studies in Part 2 show that the strong trans effect of the electron-withdrawing ligand has an accelerating effect on transmetalations through an associative mechanism. This is a very interesting observation.

5. Reductive Elimination Step. Coupling from complexes $\left[\mathrm{PdArRL}_{2}\right](6, \mathrm{R}=$ alkyl or aryl $)$ is a straightforward process with conventional aryls and phosphines at room or higher temperatures. Interestingly, PhPEWO-F promotes $\mathrm{Ar}-\mathrm{Ar}, \mathrm{Ar}-$ $\mathrm{Et}$, or Et-Et reductive eliminations at rates that are too fast to be studied. As mentioned in the Introduction, this step can be slowed down to rates appropriate for NMR studies using $\mathrm{C}_{6} \mathrm{~F}_{5},{ }^{9}$ and this conditioned the choice of the molecule for the experimental study. Monitoring by ${ }^{19} \mathrm{~F}$ NMR, reductive elimination of cis- $\left[\mathrm{Pd}\left(\mathrm{C}_{6} \mathrm{~F}_{5}\right)_{2}(\mathrm{THF})_{2}\right]$ (5) upon addition of PhPEWO-F shows that, as an isolated step, the coupling outcome depends on the Pd/PEWO ratio. Addition of 2 equiv of PhPEWO-F to 5 leads, in a few minutes, to the corresponding Pf-Pf biaryl, small amounts $(<5 \%)$ of $\mathrm{Pf}-\mathrm{H}$, and a quantitative yield of $\left[\mathrm{Pd}^{0}(\mathrm{PhPEWO}-\mathrm{F}-\mathrm{chel})_{2}\right](8)$. In contrast, addition of only 1 equiv of $\mathrm{PhPEWO}-\mathrm{F}$ produces coupling of only $50 \%$ of $\mathbf{5}$ to 8 and leaves $50 \%$ of unreacted 5 (Scheme 6). Kinetic data show that the observed coupling rate

Scheme 6. Outcome of the Pf-Pf Reductive Elimination Promoted by PhPEWO-F, Using 1 or 2 Equivalents of PhPEWO-F

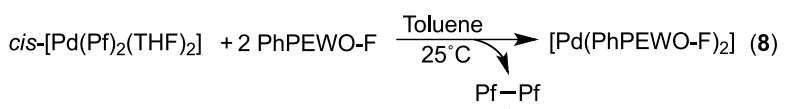

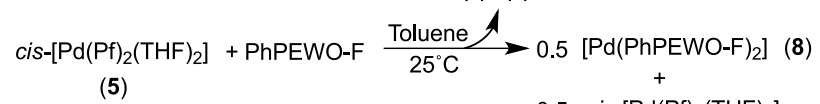

$$
\begin{aligned}
& 0.5 \text { cis- }\left[\mathrm{Pd}(\mathrm{Pf})_{2}(\mathrm{THF})_{2}\right]
\end{aligned}
$$

does not depend on the concentration of PhPEWO-F exceeding the 1:1 ratio. This supports that the reductive elimination occurs on $\left[\mathrm{Pd}(\mathrm{Pf})_{2}(\mathrm{PhPEWO}-\mathrm{F}-\mathrm{chel})\right]$, and the second PhPEWO-F ligand, when available, is incorporated at a later step.

The sequence ligand substitution/reductive elimination using 2 equiv of PhPEWO-F was monitored in toluene at low temperature $\left(-50{ }^{\circ} \mathrm{C}\right)$. The ${ }^{31} \mathrm{P}$ NMR spectra showed that formation of $\left[\mathrm{Pd}(\mathrm{Pf})_{2}(\mathrm{PhPEWO}-\mathrm{F})\right](6)$ is preferred to monodentate coordination of two phosphines, and the second equivalent of $\mathrm{PhPEWO}-\mathrm{F}$ remains free. When the temperature is allowed to rise to $25{ }^{\circ} \mathrm{C}$, coupling from 6 proceeds (Scheme $7)$, and only then the available $\left[\mathrm{Pd}^{0}(\mathrm{PhPEWO}-\mathrm{F}-\mathrm{chel})\right](7)$ captures free PhPEWO-F ligand to give $[\mathrm{Pd}(\mathrm{PhPEWO}-\mathrm{F}-$ chel $\left.)_{2}\right]$ (8).

This ligand behavior is in contrast with the observations made in the section Preliminary Test for the reaction of trans$\left[\mathrm{PdCl}_{2}(\mathrm{NCMe})_{2}\right]$ with PhPEWO-F, which affords trans$\left[\mathrm{PdCl}_{2}(\mathrm{PhPEWO}-\mathrm{F}-\mathrm{P})_{2}\right]$ (1) first and then slowly rearranges
Scheme 7. Pathway Observed in the Reaction of PhPEWO$\mathrm{F}$ with cis- $\left[\mathrm{Pd}(\mathrm{Pf})_{2}(\mathrm{THF})_{2}\right](5)$

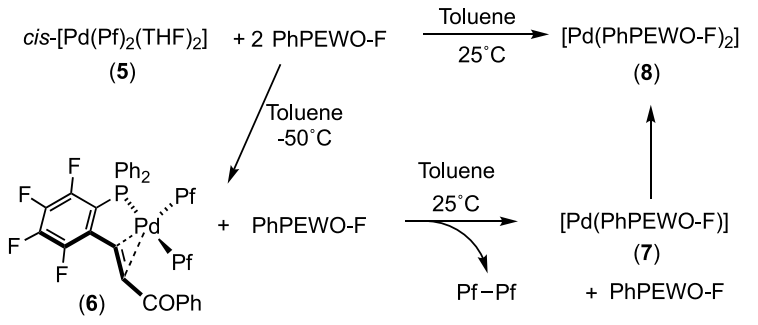

into $\left[\mathrm{PdCl}_{2}(\mathrm{PhPEWO}-\mathrm{F}-\mathrm{P})\right]$ (2) and free PhPEWO-F. This probably happens due to the lower electrophilicity of the $\mathrm{Pd}(\mathrm{Pf})_{2}$ moiety, relatively electron-rich compared to $\mathrm{PdCl}_{2}$. The higher steric congestion expected for cis-[Pd$\left.(\mathrm{Pf})_{2}(\mathrm{PhPEWO}-\mathrm{F}-\mathrm{P})_{2}\right]$ may also contribute to the disfavored formation of this intermediate. The fact is that only after coupling has occurred, the initial 14-electron reduction product $[\mathrm{Pd}(\mathrm{PhPEWO}-\mathrm{F}-\mathrm{chel})]$ (7) captures PhPEWO-F to form the much more stable 18-electron bis-chelate complex $\left[\mathrm{Pd}(\text { PhPEWO-F-chel })_{2}\right]$ (8).

The E-EWO coordination depicted in Scheme 7 was unambiguously confirmed in solution and in the solid state by NMR studies and $\mathrm{X}$-ray analysis. Complex [Pd$\left.\left(\mathrm{C}_{6} \mathrm{~F}_{5}\right)_{2}(\mathrm{PhPEWO}-\mathrm{F}-\mathrm{chel})\right]$ (6) was isolated by adding 1 equiv of PhPEWO-F to 5 at $-78{ }^{\circ} \mathrm{C}$. The addition of cold hexane $\left(-78{ }^{\circ} \mathrm{C}\right)$ provoked precipitation of 6 , which in the solid state is stable at $25^{\circ} \mathrm{C}^{22}$ Crystallization at low temperature provided single crystals and X-ray diffraction confirmed the structural features announced by the NMR spectra in solution, as well as some other structural details (Figure 3).

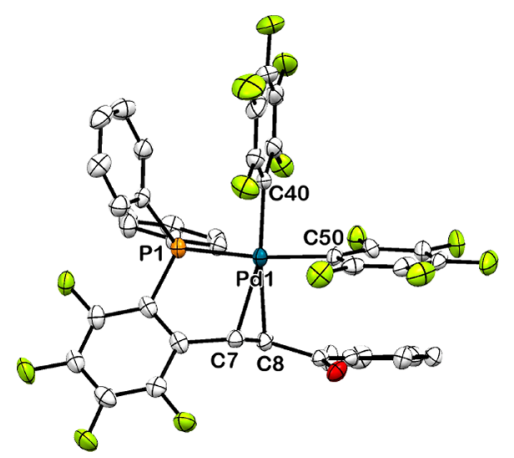

Figure 3. Structure of $\left[\mathrm{Pd}\left(\mathrm{C}_{6} \mathrm{~F}_{5}\right)_{2}(\mathrm{PhPEWO}-\mathrm{F}-\mathrm{chel})\right]$ (6), with thermal ellipsoids drawn at the $50 \%$ probability level. Hydrogen atoms are omitted for clarity. The configuration of the double bond is $E$.

The Pd atom displays a square-planar coordination defined by the two $\mathrm{C}_{\text {ipso }}$ atoms ( 40 and $\mathrm{C} 50$ ) of the $\mathrm{C}_{6} \mathrm{~F}_{5}$ groups, the $\mathrm{P}$ atom and the $(\mathrm{C} 7=\mathrm{C} 8)$ double bond, with $\mathrm{C} 8$ closer to the fourth coordination position than $\mathrm{C} 7$. The double bond shows an $E$ configuration and is disposed roughly perpendicular to the coordination plane, although in an asymmetric manner: the olefin bond and C40 occupy trans positions on $\mathrm{Pd}$, and the $\mathrm{C} 40-\mathrm{Pd}-\mathrm{C} 7$ angle is $158.2(3)^{\circ}$ (with C7 somewhat above the coordination plane), with a bond distance $\mathrm{Pd}-\mathrm{C} 7=$ 2.2842(8) $\AA$; on the other hand, the C40-Pd-C8 angle is $167.6(3)^{\circ}$ (with C2 slightly below the coordination plane), with a bond distance $\mathrm{Pd}-\mathrm{C} 2=2.320 \AA$ A The double bond 
length is $1.35(1) \AA$, which is slightly shorter than that in

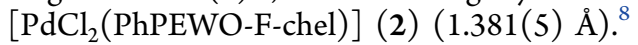

6. Exploring the Temperature Effect. In view of the effects of moderate increase in temperature observed in Scheme 4, we tested the temperature effect on a simple Negishi catalysis, using PEWO/Pd complexes in a 1:1 ratio $(2,7)$ and $2: 1(\mathbf{1}, \mathbf{8})$. Their activities were tested at $25{ }^{\circ} \mathrm{C}$ or at $60{ }^{\circ} \mathrm{C}$ for the less efficient cases. The results are gathered in Table 2. The reactions were also carried out at $60^{\circ} \mathrm{C}$.

$$
4-\mathrm{FC}_{6} \mathrm{H}_{4} \mathrm{I}+2.5 \mathrm{ZnMeCl} \underset{\mathrm{THF}, 25 \text { or } 60{ }^{\circ} \mathrm{C}}{\stackrel{5 \%[\mathrm{Pd}]}{\longrightarrow}} 4-\mathrm{FC}_{6} \mathrm{H}_{4} \mathrm{Me}
$$

Table 2. Catalytic Results for 4-FC $6 \mathrm{H}_{4}-\mathrm{Me}$ Coupling with Different Pd Complexes ${ }^{a}$

\begin{tabular}{|c|c|c|c|}
\hline$[\mathrm{Pd}]$ precatalyst & time $(\mathrm{h})$ & $T\left({ }^{\circ} \mathrm{C}\right)$ & yield (\%) \\
\hline trans $-\left[\mathrm{PdCl}_{2}(\mathrm{PEWO})_{2}\right](\mathbf{1})$ & 24 & $\begin{array}{l}25 \\
60\end{array}$ & $\begin{array}{r}32 \\
>95\end{array}$ \\
\hline$\left[\mathrm{PdCl}_{2}(\mathrm{PEWO}-\mathrm{chel})\right](\mathbf{2})$ & 5 & 25 & $>95$ \\
\hline$\left[\mathrm{Pd}\left(\mathrm{C}_{6} \mathrm{~F}_{5}\right)_{2}(\mathrm{PEWO}\right.$-chel $\left.)\right](7)$ & 5 & 25 & $>95$ \\
\hline$\left[\mathrm{Pd}(\mathrm{PEWO}-\mathrm{chel})_{2}\right](\mathbf{8})$ & 24 & $\begin{array}{l}25 \\
60\end{array}$ & $\begin{array}{l}24 \\
86\end{array}$ \\
\hline
\end{tabular}

${ }^{a}$ PEWO $=$ P-coordinate PhPEWO-F; PEWO-chel $=\mathrm{P}$, olefin chelated PhPEWO-F.

The results show that, regardless of the initial oxidation state of $\mathrm{Pd}$, the catalysts having a $\mathrm{Pd} / \mathrm{PhPEWO}-\mathrm{F}$ ratio $=1: 2$ (complexes $\mathbf{1}$ and $\mathbf{8}$ ) perform poorly at $25{ }^{\circ} \mathrm{C}$, giving low yields after $24 \mathrm{~h}$. In contrast, complexes 2 and 7, both having a Pd/ PhPEWO-F ratio $=1: 1$, perform very well, producing quantitative yields at $25^{\circ} \mathrm{C}$ in less than $5 \mathrm{~h}$. The low activity of 1 and 8 can be noticeably improved carrying out the reactions at $60{ }^{\circ} \mathrm{C}$, still a mild reaction temperature. Whether this improvement is due to some intervention of the EWO moiety along the coupling, or is simply due to the electronwithdrawing effect of these fluorinated phosphines we cannot say at the moment, but is something to be explored in catalysis.

Part 2: DFT Calculations of the $\mathrm{Ph}-\mathrm{Me}$ Negishi Cycle and the Insertion Side-Reaction. The catalytic cycle, including the coupling vs insertion competition, has been studied by DFT computations (PBE0-D3). We investigated a model Pd-catalyzed $\mathrm{sp}^{3}-\mathrm{sp}^{2}$ coupling between $\mathrm{I}-\mathrm{Ph}$ and $\mathrm{ZnMe}_{2}$ with PhPEWO-F as a ligand, in THF, affording toluene and $\mathrm{ZnMeI}$ as cross-coupling products. In addition to the description of THF as a polarizable continuum medium, two THF molecules were included as additional ligands for the zinc species (Figure 1a). ${ }^{17}$ Two structural aspects have to be considered that increase the number of species to be calculated. First of all, the initial oxidative addition of $\mathrm{Ph}-\mathrm{I}$ to $\left[\mathrm{Pd}^{0}(\mathrm{PEWO}-\mathrm{chel})\right]$ can produce two isomers with very similar activation energy: one with a cis arrangement of the $\mathrm{Ph}$ and the double bond groups (labeled -cis), and one with a trans arrangement of these groups (labeled -trans). On the other hand, the configuration of the double bond can be $E$ or $Z$.

The PEWO ligand is a 5,6,7,8- $\mathrm{F}_{4}-9$ - $\left(\mathrm{PPh}_{2}\right)$-chalcone. The most stable configuration of free chalcones is $E$. The $Z / E$ rotational isomerization barriers for other aryl-substituted chalcones in $\mathrm{MeCN}$ have been measured to be in the range $16.5-12.2 \mathrm{kcal} \mathrm{mol}^{-1}$. $^{23}$ We have recently shown that the fluorine substituents and the $\mathrm{P}$ atom (free in the free phosphine and coordinated to $\mathrm{Pd}$ in the P-coordinated complexes of the precatalysts) further reduce this rotational barrier, and $E / Z$ conformational changes are feasible and fast through similar mechanisms. ${ }^{20}$ In order to simplify the DFT analysis, we have assumed that the $E$ isomer remains throughout the reaction course as long as the alkene coordination is not disrupted. We use Roman numbers for calculated species.

Our initial attempts to model the oxidative addition step with a monoligated $[\mathrm{Pd}(\mathrm{PEWO})]$ compound (II-cis and IItrans, Figure 4) resulted in very low activation energies for the reaction between $[\mathrm{Pd}(\mathrm{PEWO})]$ and $\mathrm{Ph}-\mathrm{I}\left(\Delta G^{\ddagger}=5.1 \mathrm{kcal}\right.$ $\left.\mathrm{mol}^{-1}\right)$. Such a low energy barrier seems unlikely, due to the experimental observation that reactions with $\mathrm{Ph}-\mathrm{Br}$ are

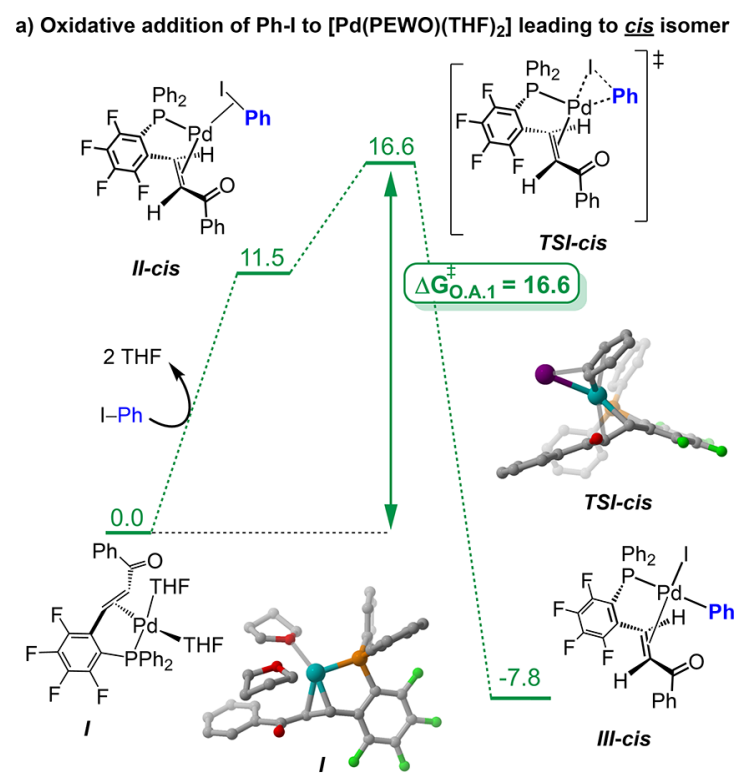

b) Oxidative addition of $\mathrm{Ph}-\mathrm{I}$ to $\left[\mathrm{Pd}(\mathrm{PEWO})(\mathrm{THF})_{2}\right]$ leading to trans isomer

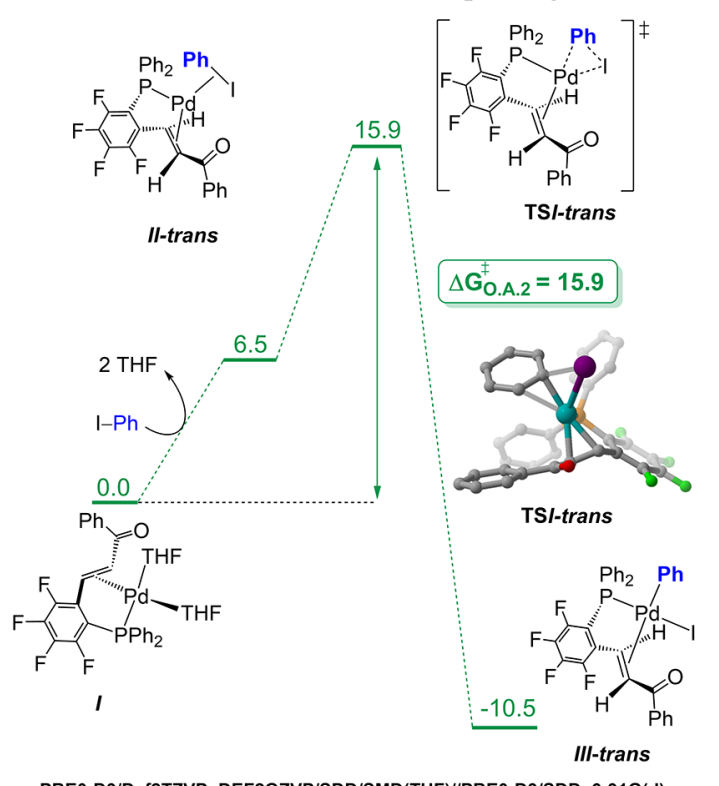

Figure 4. Gibbs energy profile of the oxidative addition step (kcal $\left.\mathrm{mol}^{-1}\right)$ for $\left[\mathrm{Pd}(\mathrm{PEWO})(\mathrm{THF})_{2}\right]$ with $\mathrm{Ph}-\mathrm{I}$. (a) Oxidative addition of $\mathrm{Ph}-\mathrm{I}$ to $\left[\mathrm{Pd}(\mathrm{PEWO})(\mathrm{THF})_{2}\right]$ leading to the cis isomer. (b) Oxidative addition of $\mathrm{Ph}-\mathrm{I}$ to $\left[\mathrm{Pd}(\mathrm{PEWO})(\mathrm{THF})_{2}\right]$ leading to the trans isomer. 
a)

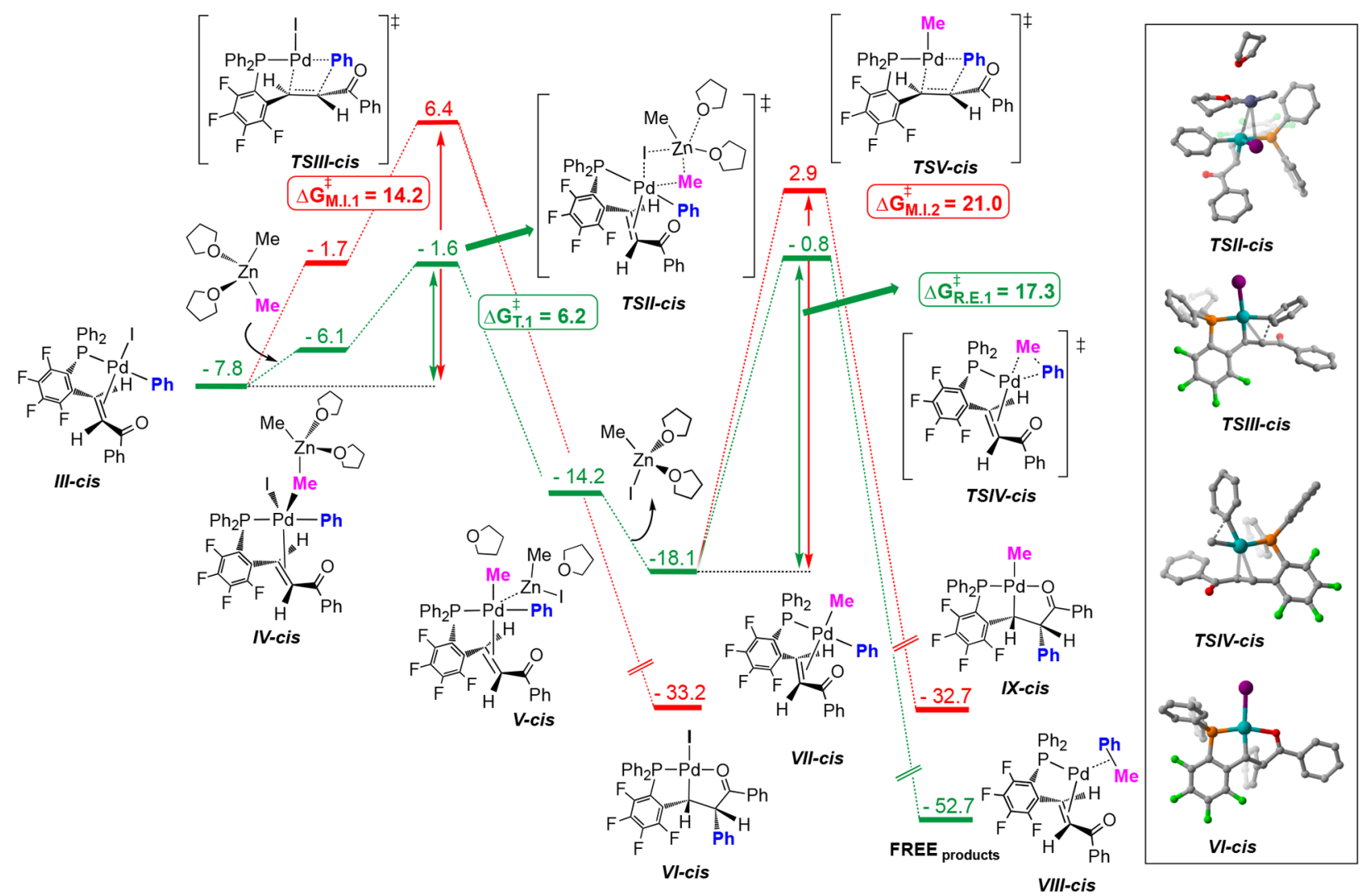

b)

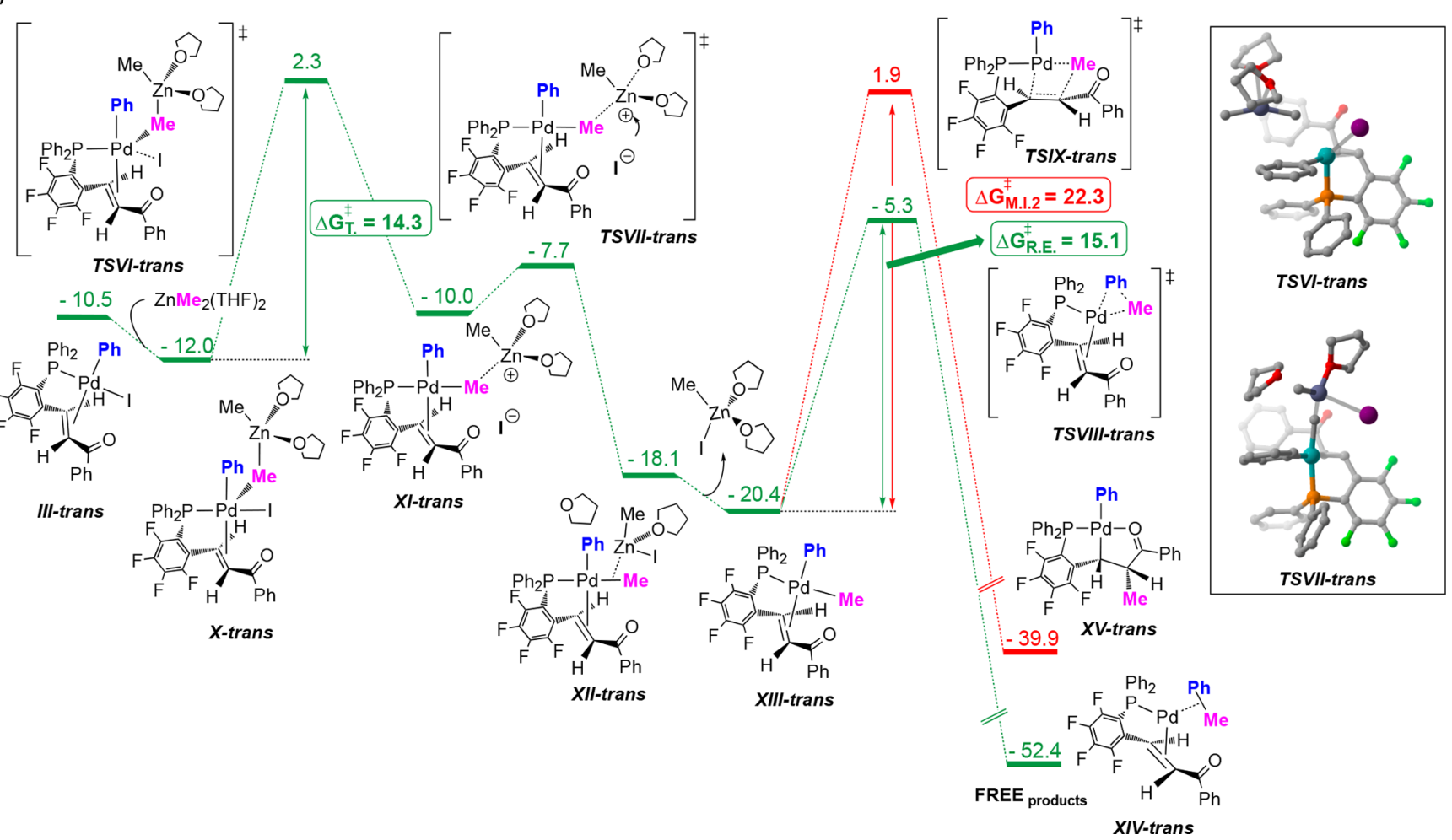

Figure 5. Gibbs energy profile of the transmetalation, migratory insertion and reductive elimination steps $\left(\mathrm{kcal}^{\mathrm{mol}} \mathrm{m}^{-1}\right)$ for cis- and trans$[\mathrm{PdI}(\mathrm{Ph})(\mathrm{PEWO})]$ (modeling 7) and $\mathrm{ZnMe}_{2}(\mathrm{THF})_{2}$. (a) Reaction coordinate for cis isomer: transmetalation, reductive elimination, and competition with alkene insertion. (b) Reaction coordinate for trans isomer: transmetalation, reductive elimination, and competition with alkene insertion. 
relatively sluggish and require heating at $60{ }^{\circ} \mathrm{C}$. Therefore, we surmised that the $\mathrm{Pd}^{0}$ complex might be present in solution as a more stable species. Through the use of cluster-continuum model, ${ }^{17}$ we found that THF molecules can stabilize the complex significantly as $\left[\mathrm{Pd}^{0}(\mathrm{PEWO})(\mathrm{THF})_{2}\right](\mathbf{I})$, which is 11.5 and $6.5 \mathrm{kcal} \mathrm{mol}^{-1}$ more stable, respectively, than the $\left[\mathrm{Pd}^{0}(\mathrm{PEWO})(\mathrm{Ph}-\mathrm{I})\right]$ adducts II-cis and II-trans. ${ }^{24,25}$ The relative stability of $\left[\mathrm{Pd}(\mathrm{PEWO})_{2}\right]$ was also investigated and was found to be a deep thermodynamic sink $\left(\Delta G_{0}=-22.7\right.$ $\mathrm{kcal} \mathrm{mol}^{-1}$, see the Supporting Information), in line with the strong decelerating effect observed experimentally in the presence of extra PEWO. Therefore, without excess ligand and in THF as solvent, we considered $\left[\mathrm{Pd}^{0}(\mathrm{PEWO})(\mathrm{THF})_{2}\right]$ (I) as the reactive form of the $\mathrm{Pd}^{0}$ complex.

Two different pathways were computed for the oxidative addition of $\mathrm{Ph}-\mathrm{I}$ to $\mathrm{I}$, depending on the orientation of the incoming $\mathrm{Ph}$ ring relative to the alkene ligand (cis or trans, Figure 4). The oxidative addition proceeds through transition states TSI-cis and TSI-trans leading to two isomers III-cis and III-trans with a slight kinetic preference for III-trans $\left(\Delta G_{\mathrm{O} . \mathrm{Al}}^{\ddagger}\right.$ $\left.=16.6 \mathrm{vs} \Delta G_{\mathrm{O} . \mathrm{A} 2}^{\ddagger}=15.9 \mathrm{kcal} \mathrm{mol}^{-1}\right)$. Although III-trans was found to be significantly more stable than III-cis $\left(G_{\text {III-cis }}=-7.8\right.$ $\mathrm{kcal} \mathrm{mol}{ }^{-1}$ vs $G_{\text {III-trans }}=-10.5 \mathrm{kcal} \mathrm{mol}^{-1}$ ) due to the larger trans influence generated by the strong $\mathrm{P}$ and $\mathrm{Ph}$ sigma donors in compound III-cis, the free energy difference between the ground states is inconsequential since the oxidative addition was found to be irreversible and therefore under kinetic control. The stereochemical outcome of the oxidative addition step is important because III-cis may lead to catalyst deactivation by migratory insertion whereas III-trans may not, given that a cis arrangement between groups to be inserted is a known prerequisite. ${ }^{26}$ Since both isomers are energetically accessible (a 3:1 ratio between III-trans and III-cis is expected

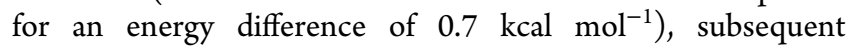
computational studies considered both isomeric pathways.

Transmetalation with $\mathrm{ZnMe}_{2}(\mathrm{THF})_{2}$ occurs through nucleophilic attack to the vacant $d_{x^{2}-y^{2}}$ orbital of III-cis by the highly electron-rich $\mathrm{Me}-\mathrm{Zn}$ bond (in green, Figure 5a), affording a trigonal bipiramidal structure IV-cis (featuring a bridging Me group, higher in energy than the free species). This intermediate rearranges into V-cis via TSII-cis by Me/I group exchange, with both exchanging groups in the equatorial plane as in classical concerted cyclic transmetalation mechanisms. ${ }^{27}$ One of the THF ligands on $\mathrm{Zn}$ is released at this point, probably due to reduced ability to accept electron density from a highly electron-rich $\mathrm{Zn}$ atom. Compound VI-cis was found to undergo reductive elimination through TS-IV

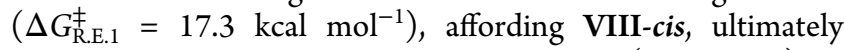
releasing toluene as a cross-coupling product (not shown).

As previously commented, compound III-cis may undergo migratory insertion of the EWO unit into the $\mathrm{Pd}-\mathrm{Ph}$ bond (in red, Figure 5a). We were able to locate the corresponding transition state for this process (TS-III-cis), which occurs with an overall activation barrier $\Delta G_{\text {M.I.1 }}^{\ddagger}=14 \mathrm{kcal} \mathrm{mol}^{-1}$. Importantly, the alkene needs to have a planar orientation with respect to the $\mathrm{Pd}-\mathrm{Ph}$ bond prior to phenyl insertion (versus $89.7 \mathrm{deg}$ of the dihedral angle between the alkene and the $\mathrm{Pd}-\mathrm{Ph}$ bond in III-cis). This alkene rotation has an energy cost of $5.9 \mathrm{kcal} \mathrm{mol}^{-1}$ (intermediate not shown in the figure). Intramolecular $\sigma$ bond rotation and carbonyl coordination affords compound VI-cis, which is very stable $\left(G_{\mathrm{VI}-c i s}=-33.2\right.$

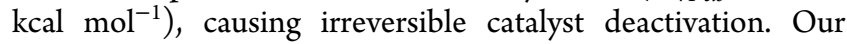
computational results support that a fast transmetalating reagent able to outcompete the intramolecular migratory insertion process is critical for a successful coupling with catalysts based on PEWO ligands, which would otherwise deactivate after a few catalytic cycles. With $\mathrm{ZnMe}_{2}$, transmetalation is much faster than migratory insertion $\left(\Delta G_{\mathrm{T} .1}^{\ddagger}=\right.$ $6.2 \mathrm{kcal} \mathrm{mol}^{-1}$ vs $\left.\Delta G_{\mathrm{T} .1}^{\neq}=14.2 \mathrm{kcal} \mathrm{mol}^{-1}\right)$. These results explain the superior performance of organozinc reagents when Pd-PEWO catalysts are employed, showcasing their strong transmetalating power. Concentration effects also need to be taken into consideration (since this is a competition between a bimolecular and a unimolecular reaction), and some excess of $\mathrm{ZnMe}_{2}$ would probably be optimal for a longer catalyst lifetime.

Similarly, compound VII-cis can be subjected to a competition between migratory insertion and reductive elimination (both unimolecular reactions). For VII-cis, Pd$\mathrm{Ph}$ insertion across the EWO occurs through TS-V $\left(\Delta G_{\mathrm{M} .22}^{\ddagger}=\right.$ $21.0 \mathrm{kcal} \mathrm{mol}^{-1}$ ) in route to IX-cis, whereas reductive elimination to form VIII-cis (and ultimately the reaction products) proceeds through a lower energy barrier (TS-IV, $\left.\Delta G_{\mathrm{R} . \mathrm{E} 1}^{\ddagger}=17.3 \mathrm{kcal} \mathrm{mol}^{-1}\right)$, suggesting that undesired migratory insertion is probably not a competitive process at this stage. The higher activation barrier for migratory insertion for VII-cis than that of III-cis suggest that, despite the fact that VII-cis is the more electron rich complex and therefore the $\mathrm{Pd}-\mathrm{Ph}$ bond should be more nucleophilic, the most important factor is the stronger activation of the EWO group at the more electrophilic III-cis.

Regarding the reaction coordinate for the trans isomer (Figure 5b), we were unable to locate a transition state analogous to TSIII-cis but corresponding to a concerted cyclic transmetalation between III-trans and $\mathrm{ZnMe}_{2}(\mathrm{THF})_{2}$. Instead, we found a different and stepwise mechanism for group exchange that occurs through exergonic association via a square pyramidal structure X-trans (through similar orbital interactions to those described for III-cis, Figure 4), followed by iodide substitution by $\mathrm{ZnMe}_{2}(\mathrm{THF})_{2}$ via trigonal bipyramidal TSVI-trans $\left(\Delta G^{\ddagger}=14.3 \mathrm{kcal} \mathrm{mol}^{-1}\right)$, leading to an ion pair XI-trans where a cationic $\mathrm{Zn}$ fragment is stabilized by the electron-rich Pd-Me bond. The methyl transfer occurs with inversion of stereochemistry through a hypervalent carbon in an open transition state. ${ }^{28}$ The proximal iodide anion attacks the highly electrophilic $\mathrm{ZnMe}(\mathrm{THF})_{2}{ }^{+}$fragment via TSVII-trans through a low activation barrier $\left(\Delta G^{\ddagger}=2.3\right.$ $\mathrm{kcal} \mathrm{mol}^{-1}$ ), leading to the collapse of the ion pair into XIItrans, which ultimately can separate into the free species XIIItrans and $\mathrm{ZnMeI}(\mathrm{THF})_{2}$.

The preference for an open transition state for the transfer of a Me group in III-trans was unexpected due to the lack of functional groups able to attenuate the excess of electron density of typically high in energy hypervalent carbons, as recently shown by Sakaki. ${ }^{29}$ We believe that the explicit solvent molecules included as ligands for $\mathrm{ZnMe}_{2}(\mathrm{THF})_{2}$ might play an important role stabilizing the $\mathrm{ZnMe}(\mathrm{THF})_{2}{ }^{+}$fragment.

As to why a cyclic mechanism is preferred for III-cis, the electrostatic repulsion generated in the 5-coordinate trigonal bipyramidal TSIII-cis Pd complex is probably alleviated by the EWO moiety acting as a $\pi$-acceptor of electron density, removing electron density in the equatorial plane. This stabilizes an associative substitution. By contrast, for the trans geometry leading to TSIII-trans, the electron density of the incoming $\mathrm{Me}$ ligand cannot be stabilized by the phosphorus atom, a much weaker $\pi$-acid, precluding formation 
of a trigonal bipyramid like IV-cis with both the exchanging $\mathrm{Me}$ and I groups in the equatorial plane. Thus, stepwise displacement of the $\mathrm{I}^{-}$ligand is preferred instead. The drastically different transmetalation activation barriers for IIIcis and III-trans $\left(\Delta G_{\mathrm{T} .1}^{\ddagger}=6.2\right.$ vs $\left.\Delta G_{\mathrm{T} .2}^{\ddagger}=14.3 \mathrm{kcal} \mathrm{mol}^{-1}\right)$ exposes the accelerating effects of electron-withdrawing ancillary ligand in transmetalation reactions, which can also be regarded as classical ligand substitution reactions. ${ }^{30}$

Finally, XIII-trans undergoes reductive elimination via TSVI-trans into IX-trans, which leads to the reaction products through an activation barrier of $22.3 \mathrm{kcal} \mathrm{mol}^{-1}$. Similar to IIIcis and VII-cis, migratory insertion might be competitive with reductive elimination for this intermediate (Figure $5 b$ ), but it is significantly higher in energy $\left(\Delta G_{\text {M.I. } 3}^{\ddagger}=22.3 \mathrm{kcal} \mathrm{mol}^{-1}\right.$ vs $\Delta G_{\mathrm{T} 2}^{\ddagger}=17.3 \mathrm{kcal} \mathrm{mol}^{-1}$ ) and unlikely a source of catalyst deactivation.

\section{CONCLUSIONS}

The easily prepared PhPEWO-F ligand, representative of other possible RPEWO-F members of the same structure, is an efficient ligand to promote aryl-alkyl Negishi couplings at room temperature. The PEWO Pd catalytic species can be easily formed in situ, either from $\left[\mathrm{PdCl}_{2}(\mathrm{MeCN})_{2}\right]$ or by spontaneous reduction of $\left[\mathrm{Pd}\left(\mathrm{C}_{6} \mathrm{~F}_{5}\right)_{2}(\mathrm{THF})_{2}\right]$ upon addition of the PEWO ligand. The latter procedure is efficient for initiation of reactions with bulky $\mathrm{R}$ groups such as ${ }^{t} \mathrm{Bu}$, which fails to generate $\mathrm{Pd}^{0}$ through double transmetalation on $\left[\mathrm{PdCl}_{2}\right.$ (PhPEWO-chel)].

It is a frequent practice in Pd-catalysis that excess ligand is used to protect the transient $14 \mathrm{e}\left[\mathrm{Pd}^{0}\right]$ species from clusterization to $\mathrm{Pd}^{0}$ black or to compensate for loss of ligand (e.g., by adventitious oxidation, in the case of phosphines). In contrast, when using PhPEWO-F at room or lower temperatures, it is important to avoid ligand excess, which may detrimental, at least in reactions at room or lower temperatures. As shown in the preceding analysis, this excess can sequester $\mathrm{Pd}$ in the form of $\left[\mathrm{Pd}(\mathrm{PhPEWO}-\mathrm{F})_{2}\right]$, because this $\mathrm{Pd}^{0}$ compound can hardly be reoxidized by $\mathrm{Ar}-\mathrm{I}$ at room temperature.

The study shows that many of the potential complications envisaged for the use of the PEWO ligands do not occur in fact as far as the transmetalations are fast, because the reactions keeping the intermediates in the cycle are faster than other alternatives driving the process out of the cycle (e.g., migratory insertion or $\beta-\mathrm{H}$ elimination). Furthermore, the coordination of the EWO moiety was found to have a beneficial accelerating effect on the associative transmetalation step, which proceeds with remarkably low activation barriers because the strong trans effect of the EWO moiety stabilizes the transition state. It is very interesting that the same structural feature, coordination of the EWO moietty, is beneficial for two critical steps, transmetalation and reductive elimination.

Notwithstanding the previous caveats, the catalysts with two PEWO per Pd can become also active (although somewhat slowly) when increasing the reaction temperature to $60{ }^{\circ} \mathrm{C}$. Since the ligand is fairly stable and it does not undergo oxidation readily, the reaction conditions may be extended to higher temperatures for low reactivity cases, where other mechanisms could be operating. As mentioned at the beginning of the Results and Discussion, these directions are being explored now in more challenging couplings.

\section{EXPERIMENTAL SECTION}

All experimental descriptions and data are collected in the Supporting Information.

\section{ASSOCIATED CONTENT}

\section{Supporting Information}

The Supporting Information is available free of charge at https://pubs.acs.org/doi/10.1021/acs.organomet.1c00001.

General methods, characterization of the catalysis products, synthesis of new compounds, NMR experiments, X-ray crystallographic data, and references (PDF) Cartesian coordinates of the calculated structure (XYZ)

\section{Accession Codes}

CCDC 1575479 and 1819348 contain the supplementary crystallographic data for this paper. These data can be obtained free of charge via www.ccdc.cam.ac.uk/data_request/cif, or by emailing data_request@ccdc.cam.ac.uk, or by contacting The Cambridge Crystallographic Data Centre, 12 Union Road, Cambridge CB2 1EZ, UK; fax: +44 1223336033.

\section{AUTHOR INFORMATION}

\section{Corresponding Author}

Pablo Espinet - IU CINQUIMA/Química Inorgánica, Facultad de Ciencias, Universidad de Valladolid, 47071 Valladolid, Spain; 이이.org/0000-0001-8649-239X; Email: espinet@qi.uva.es

\section{Authors}

Estefanía Gioria - IU CINQUIMA/Química Inorgánica, Facultad de Ciencias, Universidad de Valladolid, 47071 Valladolid, Spain; 이이.org/0000-0002-3258-7390

Juan del Pozo - IU CINQUIMA/Química Inorgánica, Facultad de Ciencias, Universidad de Valladolid, 47071 Valladolid, Spain; (1) orcid.org/0000-0003-4366-7983

Agustí Lledós - Departament de Química, Universitat Autònoma de Barcelona, 08193 Cerdanyola del Valles, Spain; ○ orcid.org/0000-0001-7909-422X

Complete contact information is available at: https://pubs.acs.org/10.1021/acs.organomet.1c00001

\section{Notes}

The authors declare no competing financial interest.

\section{ACKNOWLEDGMENTS}

Financial support is gratefully acknowledged to the Spanish MINECO (Project CTQ2017-89217-P) and the Junta de Castilla y León (Project VA062G18). We thank Jaime Poncede-León for his help in some experiments.

\section{REFERENCES}

(1) (a) Tatsumi, K.; Hoffmann, R.; Yamamoto, A.; Stille, J. K. Reductive Elimination of $\mathrm{d}^{8}$-Organotransition Metal Complexes. Bull. Chem. Soc. Jpn. 1981, 54, 1857-1867. (b) Low, J. J.; Goddard, W. A. Theoretical studies of oxidative addition and reductive elimination. 2 . Reductive coupling of hydrogen-hydrogen, hydrogen-carbon, and carbon-carbon bonds from palladium and platinum complexes. Organometallics 1986, 5, 609-622. (c) Low, J. J.; Goddard, W. A. Theoretical studies of oxidative addition and reductive elimination. 3 . Carbon-hydrogen and carbon-carbon reductive coupling from palladium and platinum bis(phosphine) complexes. J. Am. Chem. Soc. 1986, 108, 6115-6128. (d) Ananikov, V. P.; Musaev, D. G.; Morokuma, $\mathrm{K}$. Theoretical Insight into the $\mathrm{C}-\mathrm{C}$ Coupling Reactions of the Vinyl, Phenyl, Ethynyl, and Methyl Complexes of Palladium 
and Platinum. Organometallics 2005, 24, 715-723. (e) Zuidema, E.; Van Leeuwen, P. W. N. M.; Bo, C. Reductive Elimination of Organic Molecules from Palladium-Diphosphine Complexes. Organometallics 2005, 24, 3703-3710. (f) Ananikov, V. P.; Musaev, D. G.; Morokuma, K. Critical Effect of Phosphane Ligands on the Mechanism of Carbon-Carbon Bond Formation Involving Palladium(II) Complexes: A Theoretical Investigation of Reductive Elimination from Square-Planar and T-Shaped Species. Eur. J. Inorg. Chem. 2007, 2007, 5390-5399.

(2) Ligand PhPEWO-F in Figure 1 is able to produces fast $\mathrm{Me}-\mathrm{Me}$ at $-30{ }^{\circ} \mathrm{C}$ while $\mathrm{C}_{6} \mathrm{~F}_{5}-\mathrm{C}_{6} \mathrm{~F}_{5}$ requires $25^{\circ} \mathrm{C}$. See ref $8 \mathrm{~b}$.

(3) (a) Natte, K.; Jagadeesh, R. V.; He, L.; Rabeah, J.; Chen, J.; Taeschler, C.; Ellinger, S.; Zaragoza, F.; Neumann, H.; Brückner, A.; Beller, M. Palladium-Catalyzed Trifluoromethylation of (Hetero)Arenes with $\mathrm{CF}_{3} \mathrm{Br}$. Angew. Chem., Int. Ed. 2016, 55, 2782-2786. (b) Nielsen, M. C.; Bonney, K. J.; Schoenebeck, F. Computational Ligand Design for the Reductive Elimination of $\mathrm{ArCF}_{3}$ from a Small Bite Angle Pd ${ }^{\mathrm{II}}$ Complex: Remarkable Effect of a Perfluoroalkyl Phosphine. Angew. Chem., Int. Ed. 2014, 53, 5903-5906. (c) Cho, E. J.; Senecal, T. D.; Kinzel, T.; Zhang, Y.; Watson, D. A.; Buchwald, S. L. Trifluoromethylation of Aryl Chlorides. Science 2010, 328, 16791681. (d) Grushin, V. V.; Marshall, W. J. Facile Ar- $\mathrm{CF}_{3}$ Bond Formation at $\mathrm{Pd}$. Strikingly Different Outcomes of Reductive Elimination from $\left[\left(\mathrm{Ph}_{3} \mathrm{P}\right)_{2} \mathrm{Pd}\left(\mathrm{CF}_{3}\right) \mathrm{Ph}\right]$ and [(Xantphos $) \mathrm{Pd}\left(\mathrm{CF}_{3}\right)$ Ph]. J. Am. Chem. Soc. 2006, 128, 12644-12645. (e) Yandulov, D. V.; Tran, N. T. Aryl-Fluoride Reductive Elimination from Pd(II): Feasibility Assessment from Theory and Experiment. J. Am. Chem. Soc. 2007, 129, 1342-1358.

(4) (a) Sather, A. C.; Buchwald, S. L. The Evolution of $\mathrm{Pd}^{0} / \mathrm{Pd}^{\mathrm{II}}$ Catalyzed Aromatic Fluorination. Acc. Chem. Res. 2016, 49, 21462157. (b) Grushin, V. V. The Organometallic Fluorine Chemistry of Palladium and Rhodium: Studies toward Aromatic Fluorination. Acc. Chem. Res. 2010, 43, 160-171.

(5) (a) Pérez-Rodríguez, M.; Braga, A. A. C.; Garcia-Melchor, M.; Pérez-Temprano, M. H.; Casares, J. A.; Ujaque, G.; de Lera, A. R.; Álvarez, R.; Maseras, F.; Espinet, P. C-C Reductive Elimination in Palladium Complexes, and the Role of Coupling Additives. A DFT Study Supported by Experiment. J. Am. Chem. Soc. 2009, 131, 36503657. (b) Pérez-Rodriguez, M.; Braga, A. A. C.; de Lera, A. R.; Maseras, F.; Alvarez, R.; Espinet, P. A DFT Study of the Effect of the Ligands in the Reductive Elimination from Palladium Bis(allyl) Complexes. Organometallics 2010, 29, 4983-4991.

(6) Albéniz, A. C.; Espinet, P.; Martín-Ruiz, B. The Pd-Catalyzed Coupling of Allyl Halides and Tin Aryls: Why the Catalytic Reaction Works and the Stoichiometric Reaction Does Not. Chem. - Eur. J. 2001, 7, 2481-2489.

(7) (a) Williams, D. B. G.; Shaw, M. L. P-Alkene Bidentate Ligands: An Unusual Ligand Effect in Pd-Catalysed Suzuki Reactions. Tetrahedron 2007, 63, 1624-1629. (b) Luo, X.; Zhang, H.; Duan, H.; Liu, Q.; Zhu, L.; Zhang, T.; Lei, A. Superior Effect of a $\pi$-Acceptor Ligand (Phosphine-Electron-Deficient Olefin Ligand) in the Negishi Coupling Involving Alkylzinc Reagents. Org. Lett. 2007, 9, 45714574. (c) Zhang, H.; Luo, X.; Wongkhan, K.; Duan, H.; Li, Q.; Zhu, L.; Wang, J.; Batsanov, Andrei S.; Howard, Judith A. K.; Marder, Todd B; Lei, A. Acceleration of Reductive Elimination of [Ar-Pd$\left.\mathrm{Csp}^{3}\right]$ by a Phosphine/electron-Deficient Olefin Ligand: A Kinetic Investigation. Chem. - Eur. J. 2009, 15, 3823-3829.

(8) (a) Gioria, E.; Martínez-Ilarduya, J. M.; García-Cuadrado, D.; Miguel, J. A.; Genov, M.; Espinet, P. Phosphines with Tethered Electron-Withdrawing Olefins as Ligands for Efficient Pd-Catalyzed Aryl-Alkyl Coupling. Organometallics 2013, 32, 4255-4261. (b) Gioria, E.; Martínez-Ilarduya, J. M.; Espinet, P. Experimental Study of the Mechanism of the Palladium-Catalyzed Aryl-Alkyl Negishi Coupling Using Hybrid Phosphine-Electron-Withdrawing Olefin Ligands. Organometallics 2014, 33, 4394-4400.

(9) Gioria, E.; delPozo, J.; Martínez-Ilarduya, J. M.; Espinet, P. Promoting Difficult Carbon-Carbon Couplings: Which Ligand Does Best? Angew. Chem., Int. Ed. 2016, 55, 13276-13280.
(10) Ponce-de-León, J.; Gioria, E.; Martínez-Ilarduya, J. M.; Espinet, P. Ranking Ligands by Their Ability to Ease $\left(\mathrm{C}_{6} \mathrm{~F}_{5}\right)_{2} \mathrm{Ni}^{\mathrm{II}} \mathrm{L} \rightarrow \mathrm{Ni}^{0} \mathrm{~L}+$ $\left(\mathrm{C}_{6} \mathrm{~F}_{5}\right)_{2}$ Coupling versus Hydrolysis: Outstanding Activity of PEWO Ligands. Inorg. Chem. 2020, 59, 18287-18294.

(11) Negishi, E. Magical Power of Transition Metals: Past, Present, and Future (Nobel Lecture). Angew. Chem., Int. Ed. 2011, 50, 67386764.

(12) (a) Haas, D.; Hammann, J. M.; Greiner, R.; Knochel, P. Recent Developments in Negishi Cross-Coupling Reactions. ACS Catal. 2016, 6, 1540-1552. (b) Thaler, T.; Haag, B.; Gavryushin, A.; Schober, K.; Hartmann, E.; Gschwind, R. M.; Zipse, H.; Mayer, P.; Knochel, P. Highly diastereoselective $\mathrm{Csp}^{3}-\mathrm{Csp}^{2}$ Negishi crosscoupling with 1,2-, 1,3- and 1,4-substituted cycloalkylzinc compounds. Nat. Chem. 2010, 2, 125-130. (c) Cárdenas, D. J. Advances in functional-group-tolerant metal-catalyzed alkyl-alkyl cross-coupling reactions. Angew. Chem., Int. Ed. 2003, 42 (4), 384-387.

(13) (a) Martin, R.; Buchwald, S. L. Palladium-Catalyzed SuzukiMiyaura Cross-Coupling Reactions Employing Dialkyl biaryl Phosphine Ligands. Acc. Chem. Res. 2008, 41, 1461-1473. (b) Yang, Y.; Niedermann, K.; Han, C.; Buchwald, S. L. Highly selective palladium-catalyzed cross-coupling of secondary alkylzinc reagents with heteroaryl halides. Org. Lett. 2014, 16, 4638-4641.

(14) (a) Eckert, P.; Sharif, S.; Organ, M. G. Salt to Taste: The Critical Roles Played by Inorganic Salts in Organozinc Formation and in the Negishi Reaction. Angew. Chem., Int. Ed. 2020, DOI: 10.1002/ anie.202010917. (b) McCann, L. C.; Organ, M. G. On the Remarkably Different Role of Salt in the Cross-Coupling of Arylzincs From That Seen With Alkylzincs. Angew. Chem., Int. Ed. 2014, 53, 4386-4389. (c) Böck, K.; Feil, J. E.; Karaghiosoff, K.; Koszinowski, K. Catalyst Activation, Deactivation, and Degradation in PalladiumMediated Negishi Cross-Coupling Reactions. Chem. - Eur. J. 2015, 21, 5548-5560. (d) Valente, C.; Çalimsiz, S.; Hoi, K. H.; Mallik, D.; Sayah, M.; Organ, M. G. The Development of Bulky Palladium NHC Complexes for the Most-Challenging Cross-Coupling Reactions. Angew. Chem., Int. Ed. 2012, 51, 3314-3332. (e) Valente, C.; Belowich, M. E.; Hadei, N.; Organ, M. G. Pd-PEPPSI Complexes and the Negishi Reaction. Eur. J. Org. Chem. 2010, 2010, 4343-4354. (f) Achonduh, G. T.; Hadei, N.; Valente, C.; Avola, S.; O’Brien, C. J.; Organ, M. G. On the role of additives in alkyl-alkyl Negishi crosscouplings. Chem. Commun. 2010, 46, 4109-4111.

(15) (a) Casares, J. A.; Espinet, P.; Fuentes, B.; Salas, G. Insights into the Mechanism of the Negishi Reaction: $\mathrm{ZnRX}$ versus $\mathrm{ZnR}_{2}$ Reagents. J. Am. Chem. Soc. 2007, 129, 3508-3509. (b) Fuentes, B.; García-Melchor, M.; Lledós, A.; Maseras, F.; Casares, J. A.; Ujaque, G.; Espinet, P. Palladium Round Trip in the Negishi Coupling of trans-[PdMeCl$\left.\left(\mathrm{PMePh}_{2}\right)_{2}\right]$ with $\mathrm{ZnMeCl}$ : An Experimental and DFT Study of the Transmetalation Step. Chem. - Eur. J. 2010, 16, 85968599. (c) García-Melchor, M.; Fuentes, B.; Lledós, A.; Casares, J.; Ujaque, G.; Espinet, P. Cationic Intermediates in the Pd-Catalyzed Negishi Coupling. Kinetic and Density Functional Theory Study of Alternative Transmetalation Pathways in the Me-Me Coupling of $\mathrm{ZnMe}_{2}$ and trans-[PdMeCl$\left.\left(\mathrm{PMePh}_{2}\right)_{2}\right]$. J. Am. Chem. Soc. 2011, 133, 13519-13526. (d) del Pozo, J.; Salas, G.; Álvarez, R.; Casares, J. A.; Espinet, P. The Negishi Catalysis: Full Study of the Complications in the Transmetalation Step and Consequences for the Coupling Products. Organometallics 2016, 35, 3604-3611.

(16) Liu, Q.; Lan, Y.; Liu, J.; Li, G.; Wu, Y.-D.; Lei, A. Revealing a Second Transmetalation Step in the Negishi Coupling and Its Competition with Reductive Elimination: Improvement in the Interpretation of the Mechanism of Biaryl Syntheses. J. Am. Chem. Soc. 2009, 131, 10201-10210.

(17) Del Pozo, J.; Pérez-Iglesias, M.; Álvarez, R.; Lledós, A.; Casares, J. A.; Espinet, P. Speciation of $\mathrm{ZnMe}_{2}, \mathrm{ZnMeCl}$, and $\mathrm{ZnCl}_{2}$ in Tetrahydrofuran (THF), and Its Influence on Mechanism Calculations of Catalytic Processes. ACS Catal. 2017, 7, 3575-3583.

(18) Budiman, Y. P.; Jayaraman, A.; Friedrich, A.; Kerner, F.; Radius, U.; Marder, T. B. Palladium-Catalyzed Homocoupling of Highly Fluorinated Arylboronates: Studies of the Influence of Strongly vs. 
Weakly Coordinating Solvents on the Reductive Elimination Process. J. Am. Chem. Soc. 2020, 142 (13), 6036-6050.

(19) Full characterization and X-ray structures of complexes $\mathbf{1}$ and 2 can be found in ref $8 \mathrm{a}$.

(20) A careful study of this isomerization was published recently: Peñas-Defrutos, M. N.; Vélez, A.; Gioria, E.; Espinet, P. E-Z Isomerization of Phosphine-Olefin (PEWO- $\mathrm{F}_{4}$ ) Ligands Revealed upon $\mathrm{PdCl}_{2}$ Capture: Facts and Mechanism. Organometallics 2019, 38, 4701-4707.

(21) delPozo, J.; Gioria, E.; Espinet, P. Olefin Insertion Versus Cross-Coupling in trans- $\left[\mathrm{Pd}(\mathrm{Ar}) \mathrm{X}\left(\mathrm{AsPh}_{3}\right)_{2}\right]$ Complexes $(\mathrm{X}=\mathrm{I}, \mathrm{F}$, $\mathrm{CF}_{3}$ ) Treated with a Phosphine-EWOlefin Ligand to Induce Ar-X Coupling. Organometallics 2017, 36, 2884-2890.

(22) For long period storage, $T<-25^{\circ} \mathrm{C}$ is recommended.

(23) Roque, A.; Lima, J. C.; Parola, A. J.; Pina, F. Substitution and solvent effects in the chalcones isomerization barrier of flavylium photochromic systems. Photochem. Photobiol. Sci. 2007, 6, 381-385.

(24) The relatively large energy difference between II-cis and II-trans has a simple reason. In the two structures, Pd interacts with I, with $\mathrm{C}_{\text {ipso }}$, with one $\mathrm{C}_{\text {ortho, }}$ with the two EWO carbon atoms, and with the $\mathrm{P}$ atom. Most of the distances are not significantly different for intermediates II-cis and II-trans. As an exception, $\mathrm{Pd}-\mathrm{C}_{\mathrm{ipso}}$ is shorter in II-cis than in II-trans ( 2.186 vs $2.254 \AA$ ), $\mathrm{Pd}-\mathrm{I}$ is much shorter (3.073 vs $3.366 \AA$ ), and $\mathrm{Pd}-\mathrm{C}_{\text {ortho }}$ is somewhat longer (2.318 vs 2.294 $\AA)$. These distances indicate that the oxidation process is noticeably more advanced (hence closer in energy to the transition state) in IIcis.

(25) Other species such as $[\mathrm{Pd}(\mathrm{PEWO})($ toluene $)]$ were considered (since toluene is the product of the computed model reaction), but they were found to be less stable than I, see the Supporting Information for details.

(26) Thorn, D. L.; Hoffmann, R. The Olefin Insertion Reaction. J. Am. Chem. Soc. 1978, 100, 2079-2090.

(27) Casado, A. L.; Espinet, P. Mechanism of the Stille reaction. 1. The transmetalation step. Coupling of $\mathrm{R}^{1} \mathrm{I}$ and $\mathrm{R}^{2} \mathrm{SnBu}_{3}$ catalyzed by trans- $\left[\mathrm{PdR}^{1} \mathrm{IL}_{2}\right]\left(\mathrm{R}^{1}=\mathrm{C}_{6} \mathrm{Cl}_{2} \mathrm{~F}_{3} ; \mathrm{R}^{2}=\right.$ vinyl, 4-methoxyphenyl; $\mathrm{L}=$ $\left.\mathrm{AsPh}_{3}\right)$. J. Am. Chem. Soc. 1998, 120, 8978-8985.

(28) Casado, A. L.; Espinet, P.; Gallego, A. M. Mechanism of the Stille Reaction. 2. Couplings of Aryl Triflates with Vinyltributyltin. Observation of Intermediates. A More Comprehensive Scheme. J. Am. Chem. Soc. 2000, 122, 11771-11782.

(29) Zheng, H.; Semba, K.; Nakao, Y.; Sakaki, S. How to Control Inversion vs Retention Transmetalation between $\mathrm{Pd}^{\mathrm{II}}-$ Phenyl and $\mathrm{Cu}^{\mathrm{I}}$-Alkyl Complexes: Theoretical Insight. J. Am. Chem. Soc. 2017, 139 (40), 14065-14076.

(30) Ariafard, A.; Lin, Z.; Fairlamb, I. J. S. Effect of the leaving ligand $\mathrm{X}$ on transmetalation of organostannanes (vinylSnR $\mathrm{S}_{3}$ ) with $\mathrm{L}_{\mathrm{n}} \mathrm{Pd}$ $(\mathrm{Ar})(\mathrm{X})$ in Stille cross-coupling reactions. A density functional theory study. Organometallics 2006, 25, 5788-5794. 